\title{
EFFECTS OF DIFFERENT STRETCHING PROTOCOLS ON KNEE MUSCLES STRENGTH AND POWER PARAMETERS MEASURED BY BIODEX DYNAMOMETER
}

\author{
Safet Kapo, Nusret Smajlović, Husnija Kajmović, Nedim Čović, Alen Ćirić, Mehdija Ćutuk, Almir Bejdić
}

Original scientific paper Purpose of the research was to compare the effects of dynamic and proprioceptive neuromuscular facilitation (PNF) stretching on knee isokinetic strength and power parameters. Sample size of 50 male athletes is represented as male athletes divided into sub-samples of 10 athletes at competitive level in karate $(19 \pm 2,4)$, taekwondo $(20 \pm 3,6)$, boxing $(19,8 \pm 4,3)$, football $(15,1 \pm 0,3)$ and track and field sprint $(18,3 \pm 2,6)$. Isokinetic parameters of the knee were measured using Biodex isokinetic system 3 , at two angular speeds $60 \% \mathrm{~s}$ and $180 \%$. Parameters were measured after dynamic stretching protocol and again $48 \mathrm{~h}$ later after PNF protocol. For karate and taekwondo fighters no statistically significant differences were found. For boxers, football players and sprinters the values of strength and power parameters were higher after dynamic warm-up protocol at a statistically significant level. Results of this study confirmed that dynamic stretching contributes to higher values of the strength and power of thigh muscles compared to proprioceptive neuromuscular facilitation.

Keywords: Biodex dynamometer; flexibility; power; strength

\section{Učinci različitih protokola istezanja na parametre jakosti i snage koljenog zgloba mjereni Biodex dinamometrom}

Izvorni znanstveni članak Cilj istraživanja je usporedba učinaka dinamičkog istezanja i proprioceptivne neuromuskularne facilitacije (PNF) na izokinetičke parametre jakosti i snage koljenog zgloba. Uzorak čini 50 sportaša muškog spola podijeljenih na poduzorke od 10 ispitanika takmičarske razine karate $(19 \pm 2,4)$, tekvando $(20 \pm$ $3,6)$, boksanje $(19,8 \pm 4,3)$, nogomet $(15,1 \pm 0,3)$ i atletski sprint $(18,3 \pm 2,6)$. Izokinetički parametri koljena su mjereni Biodex izokinetičkim sustavom 3, na dvije kutne brzine $60 \%$ s i $180 \%$ s. Parametri su mjereni nakon dinamičkog istezanja te 48 sati kasnije nakon PNF protokola. Kod karatista i tekvando boraca nisu utvrđene značajne statistički razlike. Kod boksača, nogometaša i sprintera parametri jakosti i snage su veći nakon protokola dinamičkog istezanja. Rezultati ovog istraživanja potvrđuju da dinamičko istezanje doprinosi ispoljavanju većih vrijednosti izokinetičkih parametara jakosti i snage.

Ključne riječi: Biodex dinamometar; fleksibilnost; jakost; snaga

\section{Introduction}

In a training process stretching is hierarchically classified in warm up part of a training session [1]. The benefits that stretching gives to the muscles are multiple and the most important for sport performance achievements are: maintaining the optimal temperature, the generation of greater muscular force, injury and muscle pain prevention, as well as increasing and reaching the full range of motion (ROM)[2,3]. Stretching training activity is applied before and after a training session as a means of increasing muscle temperature for training as well as a recovery and increase of ROM [4].

According to a wide range of authors, a standard classification of stretching is made: static, ballistic, dynamic and proprioceptive-neuromuscular facilitation stretching (PNF) [4]. Static stretching is defined as maintaining muscle in a stretched position for at least 30 seconds [5]. Advantages of static stretching are rapid ROM increase and controlled progression of flexibility abilities. Some studies have shown that static stretching negatively affects power and strength output abilities [6].

Dynamic stretching performing grounds are represented by true functional exercises specifically defined for the purpose of warm up [4]. The advantage of dynamic stretching is that muscles subjected to tension remain active throughout full range of motion. This process and condition occur when the muscle spindle is stimulated suddenly, which triggers the contraction of the muscle fibers in order to prevent possible injury due to overstretching.

PNF - proprioceptive neuromuscular facilitation is a rehabilitation stretching method developed in 1958 whose basic principle is inhibition of muscle contraction [7]. PNF consists of interval exchange of muscle contraction and stretching with the assistance (passive stretching). Contraction stimulates Golgi tendon organs (GTO), which causes muscle contraction due to autogenous inhibition and allows increased muscle extensibility [8]. Importance of muscle force output is immeasurable for efficiency and good results in sport.

Warm up is the main factor that allows the body to achieve the maximum muscular force production in evergreater range of motion without consequences or injuries.

Aim of this paper is to investigate and compare acute effects of dynamic stretching and PNF stretching combined with therapeutic method of foam rolling on strength and power performances of extensors and flexors of the knee as well as the range of motion and marking possible differences in the parameters of muscular force output on subjects of five different sports. Theoretical assumption is that increased flexibility of antagonists caused by PNF protocol can lead to an increase in parameters of strength and power, or to maintain performance levels with a possible increase in range of motion (ROM). Based on these results and the specific needs for each sport a recommendation on applying adequate stretching type will be made.

\section{Methods and materials \\ 2.1 Participants}

The study has a cross-sectional character with two separate measures without additional procedures to achieve more realistic effect estimation. Controlled randomized group of fifty $(n=50)$ male athletes was 
classified into subgroups of 10 subjects engaged in karate, taekwondo, boxing, football and athletics - sprint and represents sample size. For each of the sub-groups differences in parameters of isokinetic strength and power are determined after each stretching protocol. Specificity of sports and individual differentiation of parameters of strength and power characteristic for each sport are taken into account, so results of the research are realistic representation of the opportunities provided by stretching for each of the sports. Characteristics of the sample are displayed in Tab. 1.

Table 1 Characteristics of sample size

\begin{tabular}{|l|c|c|c|}
\hline & $\begin{array}{c}\text { Height } \pm \text { SD } \\
\mathrm{cm}\end{array}$ & $\begin{array}{c}\text { Age } \pm \text { SD } \\
\text { years }\end{array}$ & $\begin{array}{c}\text { Weight } \pm \text { SD } \\
\mathrm{kg}\end{array}$ \\
\hline Karate & $184,3 \pm 6,9$ & $19 \pm 2,4$ & $77,8 \pm 11,5$ \\
\hline Taekwondo & $181,3 \pm 9,4$ & $20 \pm 3,6$ & $74,9 \pm 12,9$ \\
\hline Box & $181 \pm 4,6$ & $19,8 \pm 4,3$ & $77,7 \pm 14,1$ \\
\hline Football & $177,3 \pm 5$ & $15,1 \pm 0,3$ & $65,8 \pm 10,2$ \\
\hline Athletic - sprint & $182,2 \pm 5,4$ & $18,3 \pm 2,6$ & $76,1 \pm 4,5$ \\
\hline
\end{tabular}

All subjects were completely healthy, without knee or muscle injuries and without neuromuscular diseases or conditions that could affect research results. All subjects are active competitors in training process ranging from 3 to 7 years with at least 13 hours of training per week. Subjects were informed about procedures of dynamic and PNF warm up in detail as well as behavior related to physical training during 48 hours gap between the two measurements in order to avoid possible fatigue that could sacrifice muscle performance.

\subsection{Measures}

To measure the parameters of muscle strength and power a Biodex System 3 isokinetic dynamometer (Biodex Medical Systems; Shirley, New York) was used. Parameters of strength and power are determined on angular speeds of $60 \% \mathrm{~s}$ and $180 \% \mathrm{~s}$ for flexors and extensors of both knees. Testing was conducted in the period between $10 \mathrm{a} . \mathrm{m}$. and $11 \mathrm{a} . \mathrm{m}$. in time of greatest range of motion (ROM) ability [9]. Each subject after warm-up protocol performed five maximal voluntary contractions using involved (dominant) and uninvolved (undominant) leg.

The basic measured variables are: peak torque (PT), time to peak torque (tPT), total work (TW), average power (AP), and range of motion (ROM). According to anthropometric measures of lower extremity, Biodex apparatus for measuring isokinetic parameters has been adjusted during each measurement, just like the sitting position of the subjects according to Drouin [10].

\subsection{Dynamic warm-up procedure}

After riding bicycle ergometer for $10 \mathrm{~min}$. at a load of $50 \mathrm{~W}$ subjects performed a set of 10 dynamic stretching exercises whose sequence is shown in Fig 1. Each exercise was performed once -5 repetitions unilaterally. The full proceedings of warm up lasted on average $18 \div$ 20 minutes. Each subject after calibration performed two trial attempts and major test of five maximal voluntary contractions with highest intensity. The recovery period between the measurement of the strength and power at speeds of $60 \%$ and $180 \%$ was $30 \mathrm{~s}$.

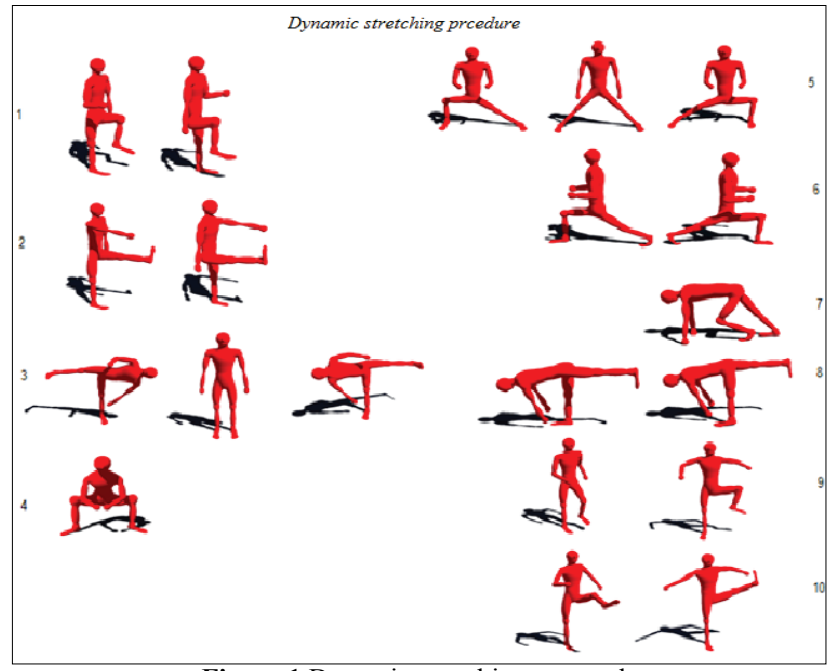

Figure 1 Dynamic stretching protocol

\subsection{Foam roller - PNF warm up procedure}

This protocol as shown in Fig. 2 was performed $48 \mathrm{~h}$ after dynamic warm-up protocol. Foam roller was used for warm up and to cause inhibition of muscles contraction by reducing the sensitivity of muscle spindles in order to determine the effect of parameters of strength and power combined with PNF stretching. Muscles treated with foam rolling and PNF stretching were lower leg back muscles, back and front thigh muscles. Each subject used foam roller to massage the mentioned muscle groups for a period of 15 seconds after which contained pressure of skating on most painful place for $30 \mathrm{~s}$ and then again massaged entire muscle group for $15 \mathrm{~s}$ [11].

After that PNF stretching was performed for group of back and front thigh muscle in a hold - relax way with a contraction of agonist $[12,13]$ : passive stretching $10 \mathrm{~s}$ passive stretching along isomeric contraction of $10 \mathrm{~s}$ passive stretching along isomeric contraction of agonist $10 \mathrm{~s}$

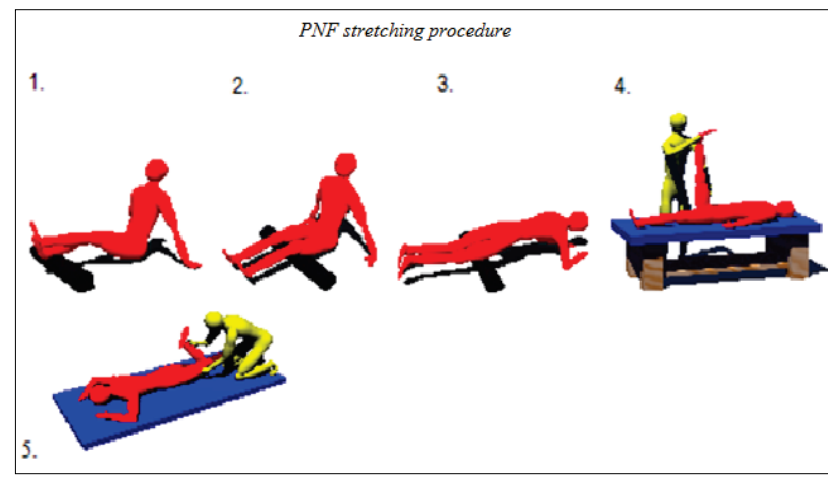

Figure 2 PNF stretching protocol

Theoretically, this protocol helps to reach maximum range of motion (ROM). Each exercise was performed in one batch for each leg separately. Two researchers did foam rolling and PNF stretching procedure using stopwatch and directions made by authors. 


\subsection{Statistical analysis}

Data analysis was conducted using software package SPSS 22.0 (SPSS IBM Corp.) and Excel (version 2007; Microsoft Corp.). Data were manually input from outprint of Biodex system into a matrix and basic measures of variability and central tendencies of data were calculated. Statistically significant differences of strength and power for dynamic and PNF stretching procedure were checked at univariate level using T-test for two dependent groups (paired samples T test).

Contents of Tabs. 2 and 3 are displaying statistically significant differences in all variables provided by Biodex system (a total of 312 variables flexion and extension involved and uninvolved leg on both speeds). In order to better display the results, the graphic of difference between peak torque (PT) results for each of sports was made and significant differences in percentages table for PT, tPT, TW, AP and ROM as well.

\section{Results}

All variables have distribution of data within a normal range, and can be used for further analysis. Based on the results of T-test for two dependent groups (Tabs. 2 and 3) statistically significant difference in at least one of the basic variables of strength and power was found. In analyzing parameters of strength and power at a speed of $60 \%$ there are significant differences for parameters of strength and power for each sport individually. In subsample of karate subjects for variables of power and strength: peak torque PT, time to peak torque tPT, total work TW, average power AP and range of motion ROM show no statistically significant differences between protocols.

Subsample of taekwondo subjects at a speed of $60 \% \mathrm{~s}$ showed no difference in basic parameters of strength and power: peak torque, time to peak torque, total work, average power, ROM.

Subjects involved in boxing at the operating speed of $60 \%$ s showed statistically significant difference from the basic parameters of strength and power. Variable peak torque (PT) in absolute value shows differences in both leg extensions involved ( $t=2,79 ; p=0,021)$, uninvolved $(t=4,12 ; p=0,008)$, as well as in uninvolved flexion $(t=$ $3,71 ; p=0,005)$ in favor of dynamic protocol. Variable time to peak torque (tPT) involved flexion showed a statistically significant difference $(t=-2,53 ; p=0,032)$ in favor of a dynamic warm-up protocols - inverse results (higher value indicates a worse outcome). Variable total work (TW) uninvolved extension shows statistically significant difference in favor of a dynamic warm-up protocol $(t=2,48 ; p=0,035)$. Variable average power (AP) showed statistically significant differences in favor of dynamic protocols in involved extension $(t=3,29 ; p=$ $0,009)$, involved flexion ( $t=2,59 ; p=0,009)$, uninvolved flexion $(t=3,6 ; p=0,006)$. Subsample of football subjects indicates statistically significant differences in the parameters of strength and power in basic variables: variable peak torque (PT) uninvolved flexion showed a statistically significant difference in favor of a dynamic warm-up protocol $(t=2,93 ; p=0,017)$, time to peak torque (tPT) involved extension $(t=-2,51 ; p=0,033)$, total work (TW) involved extension $(t=3,11 ; p=0,011)$, average power (AP) uninvolved extension $(t=4,60 ; p=$ $0,001)$, involved flexion $(t=2,86 ; p=0,019)$, with better results for protocol of dynamic warm-up.

Subsample-athletes sprint also showed significant differences in the parameters of strength and power to the speed of $60 \%$ conditioned by different stretching protocol. Significant differences in the basic parameters of power were found in variable peak torque (PT) involved extension $(t=5,06 ; p=0,001)$, uninvolved extension $(t=2,56 ; p=0,031)$, involved flexion $(t=$ $2,83 ; p=0,02)$ in favor of better results after the dynamic protocol of warm up. Parameter time to peak torque (tPT) involved flexion $(t=-2,92 ; p=0,017)$ showed better results in favor of dynamic stretching protocol (inverse result). Results in variables total work (TW) uninvolved extension $(t=2,83 ; p=0,02)$, uninvolved flexion $(t=$ $2,48 ; \quad p=0,035)$ provide statistically significant differences in favor of the results of strength and power after the dynamic warm up protocol. Average power (AP) involved extension $(t=4,35 ; p=0,002)$, involved flexion $(t=3,34 ; p=0,009)$, uninvolved flexion $(t=2,89 ; p=$ $0,018)$ also showed significant differences in level of strength and power higher after dynamic warm-up procedures.

Power and strength parameters at speed of $180^{\circ} / \mathrm{sec}$. have similar results of sub-samples and their basic parameters of strength and power show differences except for subsample group of karate and taekwondo fighters who did not show statistically significant differences in the basic parameters of strength and power conditioned by different protocols, dynamic and PNF stretching.

Subsample of boxers showed statistically significant differences in the basic parameters of strength and power. Variable peak torque (PT) involved extension $(t=4,04 ; p$ $=0,003)$, uninvolved extension $(t=2.26 ; p=0.005)$, involved flexion $(t=2,3 ; p=0,047)$ and uninvolved flexion $(t=3,19 ; p=0,011)$ showed higher values after a dynamic warm-up protocol. The variable time to peak torque (tPT) showed no significant changes and differences caused by different stretching protocols. Variable total work (TW) involved extension $(t=3,31 ; p$ $=0,009)$ and uninvolved flexion $(t=5,38 ; p=0,000)$ show statistically significant differences in favor of dynamic warm-up protocol. Variable average power (AP) involved extension $(t=2,84 ; p=0,019)$, uninvolved extension $(t=2,38 ; p=0,041)$ and uninvolved flexion $(t$ $=4,76 ; p=0,001)$ show significant differences and better results after a dynamic warm-up protocol. Interestingly, the variable range of motion (ROM) uninvolved extension $(t=2,5 ; p=0,034)$ and uninvolved flexion $(t=2,5 ; p=$ $0,034)$ were statistically better after a dynamic warm-up protocol.

Group of football players shows significant differences in the basic parameters and the time to peak torque (tPT) uninvolved extension $(t=-3,34 ; p=0,009)$, total work (TW) involved flexion $(t=2,52 ; p=0,032)$, average power (AP) involved extension $(t=2,27 ; p=$ $0,049)$ and involved flexion $(t=3,16 ; p=0,012)$ with better results after dynamic warm-up protocol.

Subsample of subjects training sprint events at speed of $180 \%$, showed statistically significant differences in the basic parameters of strength and power: variable peak 
torque (PT) involved extension $(t=3,56 ; p=0,006)$, uninvolved extension $(t=2.56 ; p=0.031)$, involved flexion $(t=3,73 ; p=0,005)$ and uninvolved flexion $(t=$ $3,69 ; p=0,005)$, time to peak torque (tPT) involved extension $(t=-2,58 ; p=0,03)$ (inverse score-value), total work (TW) uninvolved extension $(t=2,53 ; p=$ $0,032)$ and average power (AP) involved extension $(t=$ $3,74 ; p=0,005$,$) uninvolved extension (t=2,32 ; p=$ $0,046)$ in favor of the results measured after the dynamic stretching protocol. Peak torque result differences are obvious and clear out in Fig. 3.

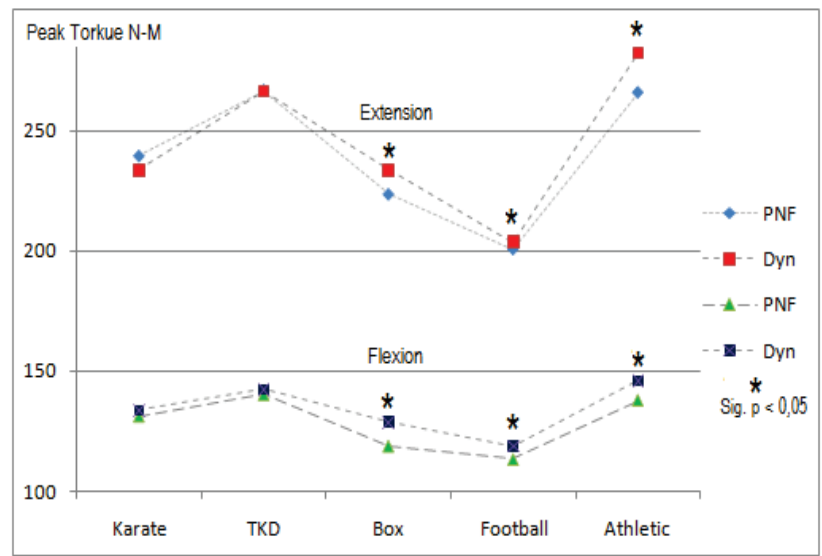

Figure 3 Peak torque output for dynamic and PNF stretching protocol

Table 2 Significant differences in main power and strength parameters for dynamic stretching protocol in percentages

\begin{tabular}{|c|c|c|c|c|c|}
\hline & $\mathrm{PT} / \%$ & $\mathrm{tPT} / \%$ & $\mathrm{TW} / \%$ & $\mathrm{AP} / \%$ & $\mathrm{ROM} / \%$ \\
\hline \multirow{4}{*}{ Box } & 2,7 & & & 4,1 & \\
\hline & 5,9 & & & & \\
\hline & & 26,6 & & 8,7 & \\
\hline & 9,6 & & 7 & 10 & \\
\hline \multirow{3}{*}{ Football } & & $-6,7$ & 7,4 & & \\
\hline & & & & 7,3 & \\
\hline & 7,2 & & & 6,6 & \\
\hline \multirow{4}{*}{ Athletic } & 5,7 & & & 7,8 & \\
\hline & 6 & & 7,8 & & \\
\hline & 5,5 & 23 & & 4,6 & \\
\hline & & & 9,1 & 7,2 & \\
\hline Karate & \multicolumn{5}{|c|}{ No significant differences in PT, tPT, TW, AP, ROM } \\
\hline Taekwondo & \multirow{2}{*}{\multicolumn{5}{|c|}{$\frac{\text { No significant differences in PT, tPT, TW, AP, ROM }}{60 \% \mathrm{~s}}$}} \\
\hline & & & & & \\
\hline & $\mathrm{PT} / \%$ & $\mathrm{tPT} / \%$ & TW / \% & $\mathrm{AP} / \%$ & $\mathrm{ROM} / \%$ \\
\hline \multirow{4}{*}{ Box } & 4,5 & & 6,3 & 7,1 & \\
\hline & 6,1 & & & 7,6 & 4,9 \\
\hline & 9,1 & & & & \\
\hline & 10,5 & & 13,8 & 13,7 & 0,4 \\
\hline \multirow{3}{*}{ Football } & & & & 4 & \\
\hline & & $-21,7$ & & & \\
\hline & & & 5,6 & 6,9 & \\
\hline \multirow{4}{*}{ Athletic } & 6 & 10,7 & & 7,6 & \\
\hline & 5,5 & & 5,6 & 5 & \\
\hline & 6 & & & & \\
\hline & 7,7 & & & & \\
\hline Karate & \multicolumn{5}{|c|}{ No significant differences in PT, tPT, TW, AP, ROM } \\
\hline Taekwondo & \multirow{2}{*}{\multicolumn{5}{|c|}{ No significant differences in PT, tPT, TW, AP, ROM }} \\
\hline & & & & & \\
\hline
\end{tabular}

Individual percentage differences of dynamic stretching protocols in relation to the procedure foam rolling with PNF stretching are shown in Tab. 2.

Looking at the basic differences in parameter peak torque (PT) at a speed of $60 \%$ s. they move ranging from $2,7 \%$ to $9,6 \%$ with better results after dynamic stretching. At operating speed of $180 \%$ sec knee peak torque output greater values after dynamic stretching ranging from $4,5 \%$ to $10,5 \%$. Variable time to peak torque (tPT) at a speed of $60 \%$ sec shows that after the protocol of dynamic stretching in relation to PNF stretching athletes gain power faster at greater peak torque values in percentage between $23 \div 26,6 \%$, and at a speed of $180 \%$ football players had better results after PNF protocol by $21,7 \%$ and athletes by $10 \%$ faster time to peak torque after protocol of dynamic stretching. Value differences with better results after a dynamic warm-up protocols in total work (TW) at a speed of $60 \%$ range from $7 \div 9,1 \%$ and at a speed of $180^{\circ} / \mathrm{sec}$ from 5,9 to $13,8 \%$. Values of average power (AP) at a speed of $60 \%$ after dynamic stretching protocol are higher than the PNF stretching protocol an average of $4,1 \div 10 \%$, and at operating speed of $180 \%$ increased by $4 \div 13,7 \%$. Range of motion (ROM) showed that a greater range of motion is achieved after a dynamic warm-up protocols in boxers at a speed of $180 \%$ of $0,4 \div 4,9 \%$.

\section{Discussion}

The task to research and determine levels and differences of knee extensors and flexors strength and power parameters among athletes after a warm-up protocol of dynamic stretching and after the protocol procedures that combine myofascial massage with inhibition of muscle spindle and proprioceptive neuromuscular facilitation assisted (PNF) stretching according to the protocol hold - relax with agonist contraction showed expected results. Various researches on the effects of dynamic stretching and PNF stretching on the parameters of strength and power suggest that dynamic stretching improves power output. From results of this research it can be concluded that there are differences between the parameters of strength and power caused by different protocols of stretching.

Looking at the global results of the complete survey it can be said that dynamic stretching contributes to a better force production for boxing, football and athletics. Karate and taekwondo fighters had not provided statistically significant differences in basic parameters of strength and power between two stretching procedures.

Compared to proprioceptive neuromuscular facilitation (PNF) dynamic stretching contributes to a better output of strength and power parameters on this sample. Lower values in variables of power, strength and muscle activation at a speed of $60 \%$ appear when PNF stretching is applied [14], and dynamic stretching contributes to a greater manifestation of strength and power [15]. It is noted that the results in the countermovement jump test after PNF stretching are significantly lower, and that forces manifestations decreased drastically after PNF stretching. Reduction of peak torque parameters and variables of strength and power after PNF stretching may be incurred as a result of muscle fatigue induced in the active phase hold - relax procedure [16]. Based on these results of their research, Khorasani and Kellis[17] suggested that dynamic stretching is probably more effective in increasing quadriceps muscle activity and knee extension angular velocity. These results suggest that dynamic stretching is ideal for warm up in order to 
achieve maximum force performance of knee extensors and flexors. Reasons for appliance of dynamic stretching in order to achieve maximum performance theoretically lies in the fact that respondents willing contraction speed up nervous apparatus, and achieve higher muscle temperature that becomes more energy-stocked due to increased vasodilatation. A reason more is possible response and appearance of post - activation potential induced by voluntary muscle contractions [18].

Most of these researches were conducted on a sample of subjects who are not on a competitive level in sport therefore the importance of this work is multifaceted. Studies conducted on the effects of passive stretching on peak torque (PT) generally have resulted in lower level of result values at low speeds of movement performance [19]. Given that passive stretching is part of standard procedures of PNF stretching, lower operational performance results of strength and power may be based on this theory. Results of this study on athletes, have found that there are no differences in parameters of strength and power at different work speeds. Differences between output of power and strength for the existence in both low and high angular velocities of work are similar in both protocols of dynamic and PNF stretching. Based on these findings it can be concluded that PNF stretching has equally negative impact on the sport of strength and fortitude.

Reviewing the performance of thigh muscles in subsample of karate fighters and taekwondo fighters, it is obvious that there were no statistically significant differences in the parameters of strength and power that could be caused by different protocols of stretching. Analyzing the movement and structure of strokes in these sports and their leg techniques, where significant role has ability of reducing the distance over hitting power, it can be concluded that the range of motion is capability of higher importance during competitions. Of course, this study found no differences in range of motion (ROM) between the dynamic and PNF stretching. Given that the measurement of ROM was performed on Biodex isokinetic dynamometer it can be said that knee joint range of motion is just part of maximum range of motion in sport specific movement.

PNF stretching methods with reduced pain while stretching (foam rolling) improve range of motion (ROM) [14]. On the basis of the results of this research and already mentioned peer - reviewed papers, it can be concluded that reasonable warm up stretching for karate and taekwondo is PNF stretching assisted with foam rolling because it does not affect the strength and power of knee extensors and flexors and on the other hand proprioceptive neuromuscular facilitation stretching can increase range of motion [14, 20, 21].

Main characteristic of boxing, football, and track and field sprint discipline is fast and dynamic operation of the lower extremities. Movements that meet specifications based and used by athletes of mentioned sports are highly correlated with agility and sprint abilities that depend on high output of strength and power produced by thigh muscles [22]. It is the amount of muscle force that contributes to the success of execution of motor tasks efficiently and without fatigue. Thus, heat can play a crucial role, especially in athletics sprint events where contestant performance must benefit from all resources of strength and fortitude. Results showed that dynamic stretching provides significantly better strength of thigh muscles in relation to PNF stretching assisted with myofascial massage and inhibition of muscle spindles. Values in percentages are significantly higher especially at lower leg extension. Significant differences in flexion and extension of both upper legs in variable peak torque (PT) were identified in the subsample of boxers. Particularly large difference was found at $180 \%$ s. This is important as power difference of $10 \%$ can cause the violation of muscle structure.

\section{Conclusion}

Dynamic stretching can provide higher output of strength and power parameters. This can lead to overall better sport performance. Based on the results of research neither PNF nor dynamic stretching are suitable for providing increase in ROM, with limitation because ROM was measured using Biodex dynamometer.

\section{References}

[1] Hoffman, J. Physiological aspects of sport training and performance: Human Kinetics, (2014).

[2] Shrier, I. Does stretching help prevent injuries. // Evidencebased sports medicine. 9, (2002), pp. 43-47.

[3] Enoka, R. M.; Fuglevand, A. J. Motor unit physiology: some unresolved issues. // Muscle \& nerve. 24, 1(2001), pp. 4-17. DOI: 10.1002/1097-4598(200101)24:1<4::AIDMUS13>3.0.CO;2-F

[4] Bompa, T. O.; Carrera, M. Periodization training for sports (Vol. 3) / Human Kinetics Champaign (IL), (2005).

[5] Bandy, W. D.; Irion, J. M. The effect of time on static stretch on the flexibility of the hamstring muscles. // Physical therapy. 74, 9(1994), pp. 845-850.

[6] Knudson, D. V.; Magnusson, P.; McHugh, M. Current Issues in Flexibility Fitness. // President's Council on Physical Fitness and Sports Research Digest. (2000). DOl: 10.1037/e603532007-001

[7] Holt, L. E.; Travis, T. M.; Okita, T. Comparative study of three stretching techniques. // Perceptual and motor skills. 31, 2(1970), pp. 611-616. DOI: 10.2466/pms.1970.31.2.611

[8] Moore, M. A.; Hutton, R. S. Electromyographic investigation of muscle stretching techniques. // Medicine and Science in Sports and Exercise. 12, 5(1979), pp. 322329. DOI: 10.1249/00005768-198025000-00004

[9] Ozolin, N. Sovremennaia systema sportivnoi trenirovky (Athlete's training system for competition). Moscow: Fizkultura I Sport (1971).

[10] Drouin, J. M.; Valovich-mcLeod, T. C.; Shultz, S. J.; Gansneder, B. M.; Perrin, D. H. Reliability and validity of the Biodex system 3 pro isokinetic dynamometer velocity, torque and position measurements. // European journal of applied physiology. 91, 1(2004), pp. 22-29. DOI: 10.1007/s00421-003-0933-0

[11] Fama, B. J.; Bueti, D. R. The acute effect of self-myofascial release on lower extremity plyometric performance, (2011).

[12] Moore, M. A.; Hutton, R. S. Electromyographic investigation of muscle stretching techniques. // Medicine and Science in Sports and Exercise. 12, 5(1979), pp. 322329. DOI: 10.1249/00005768-198025000-00004

[13] Sady, S. P.; Wortman, M.; Blanke, D. Flexibility training: ballistic, static or proprioceptive neuromuscular 
facilitation? // Archives of physical medicine and rehabilitation. 63, 6(1982), pp. 261-263.

[14] Marek, S. M.; Cramer, J. T.; Fincher, A. L.; Massey, L. L.; Dangelmaier, S. M.; Purkayastha, S.; . . . Culbertson, J. Y. Acute effects of static and proprioceptive neuromuscular facilitation stretching on muscle strength and power output. // Journal of Athletic Training. 40, 2(2005), p. 94.

[15] Yamaguchi, T.; Ishii, K. Effects of static stretching for 30 seconds and dynamic stretching on leg extension power. // The Journal of Strength \& Conditioning Research. 19, 3(2005), pp. 677-683.

[16] Young, W.; Elliott, S. Acute effects of static stretching, proprioceptive neuromuscular facilitation stretching, and maximum voluntary contractions on explosive force production and jumping performance. // Research quarterly for exercise and sport. 72, 3(2001), pp. 273-279. DOI: 10.1080/02701367.2001.10608960

[17] Amiri-Khorasani, M.; Osman, N. A. A.; Yusof, A. Acute effect of static and dynamic stretching on hip dynamic range of motion during instep kicking in professional soccer players. // The Journal of Strength \& Conditioning Research. 25, 6(2011), pp. 1647-1652. DOI: 10.1519/JSC.0b013e3181db9f41

[18] Sale, D. G. Postactivation potentiation: role in human performance. // Exercise and sport sciences reviews. 30, 3(2002), pp. 138-143. DOI: 10.1097/00003677-20020700000008

[19] Cramer, J. T.; Housh, T. J.; Johnson, G. O.; Miller, J. M.; Coburn, J. W.; Beck, T. W. Acute effects of static stretching on peak torque in women. // The Journal of Strength \& Conditioning Research. 18, 2(2004), pp. 236241.

[20] Sharman, M. J.; Cresswell, A. G.; Riek, S. Proprioceptive neuromuscular facilitation stretching. // Sports Medicine. 36, 11(2006), pp. 929-939. DOl: 10.2165/00007256200636110-00002

[21] Yuktasir, B.; Kaya, F. Investigation into the long-term effects of static and PNF stretching exercises on range of motion and jump performance. // Journal of bodywork and movement therapies. 13, 1(2009), pp. 11-21. DOl: 10.1016/j.jbmt.2007.10.001

[22] Negrete, R.; Brophy, J. The relationship between isokinetic open and closed chain lower extremity strength and functional performance. // JSR. 9, 1(2010).

\section{Authors' addresses}

\section{Safet Kapo, Ph.D}

Faculty of Sport and Physical Education, University of Sarajevo, Bosnia and Herzegovina,

Patriotske lige 41, 71000 Sarajevo, BiH,

E-mail:kapo.safet@gmail.com

Nusret Smajlović, Ph.D

Faculty of Sport and Physical Education, University of Sarajevo, Bosnia and Herzegovina,

Patriotske lige 41, 71000 Sarajevo, BiH,

Husnija Kajmović, Ph.D

Faculty of Sport and Physical Education, University of Sarajevo, Bosnia and Herzegovina,

Patriotske lige 41, 71000 Sarajevo, BiH,

Nedim Čović, MA

Faculty of Sport and Physical Education, University of Sarajevo, Bosnia and Herzegovina,

Patriotske lige 41, 71000 Sarajevo, BiH,

Ćirić Alen, MA

Faculty of Sport and Physical Education, University of Sarajevo, Bosnia and Herzegovina,

Patriotske lige 41, 71000 Sarajevo, $\mathrm{BiH}$

Medhdija Ćutuk, MA

Faculty of Sport and Physical Education, University of Sarajevo, Bosnia and Herzegovina,

Patriotske lige 41, 71000 Sarajevo, BiH

Almir Bejdić, MA

Faculty of Sport and Physical Education, University of Sarajevo, Bosnia and Herzegovina,

Patriotske lige 41, 71000 Sarajevo, BiH 